\title{
Changes in the drug release pattern of fresh and set simvastatin-loaded brushite cement
}

Gemma Mestres $^{1}$, Karol Kugiejko ${ }^{1}$, David Pastorino ${ }^{2}$, Johanna Unosson ${ }^{1}$, Caroline Öhman ${ }^{1,3}$, Marjam Karlsson Ott ${ }^{1}$, Maria-Pau Ginebra ${ }^{2}$, Cecilia Persson $^{1 *}$

\footnotetext{
${ }^{1}$ Materials in Medicine, Div. of Applied Materials Science, Dpt. Engineering Sciences, Uppsala University, Sweden.

${ }^{2}$ Biomaterials, Biomechanics and Tissue Engineering Group, Department of Materials Science and Metallurgy, Technical University of Catalonia (UPC), Av. Diagonal 647, 08028 Barcelona, Spain

${ }^{3}$ Div. of Applied Mechanics, Dpt. Engineering Sciences, Uppsala University, Sweden.
}

* Corresponding author

\section{* Corresponding author:}

Cecilia Persson

Division of Applied Materials Science

Dpt. of Engineering Science

The Ångström Laboratory

Uppsala University

Box 534

75121 Uppsala

E-mail: cecilia.persson@angstrom.uu.se

Telephone: +46-18 4717911

Fax : +46-18-471 3572 


\begin{abstract}
Calcium phosphate cements are synthetic bone graft substitutes able to set at physiological conditions. They can be applied by minimally invasive surgery and can also be used as drug delivery systems. Consequently, the drug release pattern from the cement paste (fresh cement) is of high clinical interest. However, previous studies have commonly evaluated the drug release using pre-set cements only. Therefore, the aim of this work was to determine if the time elapsed from cement preparation until immersion in the solution ( $3 \mathrm{~min}$ for fresh cements, and $1 \mathrm{~h}$ and $15 \mathrm{~h}$ for pre-set cements) had an influence on its physical properties, and correlating these to the drug release profile. Simvastatin was selected as a model drug, while brushite cement was used as drug carrier. This study quantified how the setting of a material reduces the accessibility of the release media to the material, thus preventing drug release. A shift in the drug release pattern was observed, from a burst-release for fresh cements to a sustained release for pre-set cements.
\end{abstract}

Keywords: brushite; calcium phosphate cement; local drug release; tortuosity; simvastatin; setting. 


\section{Introduction}

Calcium phosphate cements (CPCs) were first described in the 1980s [1,2] and have been clinically accepted in many areas of orthopaedics and dentistry [3]. These cements set at physiological temperature through a dissolution-precipitation reaction when mixing a calcium phosphate-based powder with an aqueous solution. The resulting materials have chemical and physical similarities to the inorganic phase of bone tissue [4], which is one of the reasons why CPCs are bioactive, biocompatible and osteoconductive [5]. The use of cements is advantageous in comparison with sintered calcium phosphate materials, as they can be injected into the body using minimally invasive surgery techniques. However, the cement formulations must be chosen carefully to ensure a good cohesion of the paste and appropriate injectability, which will procure an adequate confinement at the target site $[5,6]$ and clinical applicability.

The isothermal setting of CPCs together with their intrinsic porosity are advantageous when being considered as drug delivery systems since drugs generally maintain their integrity when loaded in the cement, and porosity facilitates their elution [7]. Drugs and growth factors that may either enhance bone regeneration or target specific skeletal pathologies have hence been evaluated in CPCs [7]. Enhancing bone growth is a key aspect to restore the mechanical function of the tissue, increase the osseointegration of the material and decrease the risk of posterior mechanical failure.

The drug release from CPCs has commonly been monitored using pre-set specimens, which were allowed to set for different periods, varying from 10-20 min [8], overnight [9], or $24 \mathrm{~h} \mathrm{[10-17]} \mathrm{up} \mathrm{to} 7$ days [10]. Moreover, in several studies [18-22] the conditions used were not indicated. Hence, most studies in the literature disregard the fact that the release pattern may change depending on the time the cement was set for; only Canal et al. compared the drug release patterns of cements set for different times ( $1 \mathrm{~h}$ vs 7 days), but this was done on apatitic cements only [10]. Although the importance of monitoring the drug release from fresh cement has been highlighted [7], to the best of the authors' knowledge, no previous studies have evaluated the drug release of a fresh, recently prepared cement paste. A previous study in our research group evaluated the release of simvastatin from premixed brushite cement during setting [23]. However, that study was performed on premixed 
cement, where the cement powder is mixed with glycerol and the setting reaction does not start until the mixture is put in contact with an aqueous solution, hence giving rise to a very different setting situation and drug release conditions than the aqueous mixtures commonly used.

The aim of the current work was to evaluate the drug release pattern of brushitic, aqueous cementmixtures directly after preparation, in comparison to the commonly used pre-set cement evaluations. Simvastatin was used as the model drug. This drug, besides being commonly prescribed to decrease hepatic cholesterol biosynthesis [24], has also been reported to potentially improve bone healing [25]. It stimulates the expression of bone morphogenetic protein 2 (BMP-2) in osteoblasts [26] and enhances alkaline phosphatase (ALP) activity and mineralization [27]. The drug release was monitored and modeled through Korsmeyer-Peppas (KP) equation. The handling properties of the cement paste were evaluated by cohesion, setting time and injectability tests. The structural properties of the fresh and set cements, as characterized by the crystalline phases, porosity, tortuosity, morphology and mechanical properties, were used to correlate the setting process of the paste to the release pattern of the drug. This study intended to highlight the importance of the time the cements are set for prior to implantation, since this may determine whether a therapeutic concentration is reached or not.

\section{Materials and methods}

\subsection{Cement preparation}

The cement powder was prepared by mixing $54 \mathrm{wt} \% \beta$-tricalcium phosphate $\left(\beta-\mathrm{Ca}_{3}\left(\mathrm{PO}_{4}\right)_{2}, \beta\right.$-TCP, ref. n. 21218, Sigma Aldrich, USA), 44 wt.\% $\left(\mathrm{Ca}\left(\mathrm{H}_{2} \mathrm{PO}_{4}\right)_{2} \cdot \mathrm{H}_{2} \mathrm{O}, \mathrm{MCPM}\right.$, ref. n. CA0211005P Scharlau, Germany) and 2 wt.\% sodium pyrophosphate as a retardant [28] $\left(\mathrm{Na}_{4} \mathrm{P}_{2} \mathrm{O}_{7}\right.$, SPP, ref. n. 71499, Fluka, Switzerland) for $20 \mathrm{~min}$ in a powder mixer (Turbula®, Willy A. Bachofen AG Maschinenfabrik, Germany). The MCPM was previously sieved (Retsch, Germany) down to particles smaller than $75 \mu \mathrm{m}$, to enhance the mechanical properties of brushite cement [29]. The cement was prepared by mixing the powder with an aqueous solution at a liquid to powder ratio (L/P) of $0.32 \mathrm{ml} / \mathrm{g}$ (the aforementioned $\mathrm{L} / \mathrm{P}$ value was selected to ensure a good cohesion of the cements and an adequate 
setting time). The powder was manually mixed with respective liquid phase for $45 \mathrm{~s}$ before further characterisation or moulding.

Simvastatin (Sigma Aldrich, ref. n. 79902-63-9, USA) was used as the model drug. Whereas lipophilic molecules of simvastatin (lactone) are metabolized in the liver for the reduction of cholesterol, a more hydrophilic form (hydroxyacid) is needed in hard tissues applications to potentiate its pharmacological effect $[30,31]$. The simvastatin was therefore hydrolysed to convert its isolated $\beta$-hydroxyacid form into an open ring by adding the simvastatin in an alkaline solution of ethanol/ $\mathrm{NaOH} 0.1 \mathrm{M}$ and heating it at $50{ }^{\circ} \mathrm{C}$ for $2 \mathrm{~h}[32]$. The simvastatin solution was then neutralized to $\mathrm{pH} 7.4$ and stored at $-20^{\circ} \mathrm{C}$. The liquid phase of the cement used was either distilled water for pristine cements; named C; or hydrolysed simvastatin at a concentration of $2 \mathrm{mM}$ for simvastatin-loaded cements; named s-C $(0.27$ mg simvastatin/g brushite). The concentration of the simvastatin solution was selected with three considerations in mind: 1) a simvastatin concentration between 0.01 and $1 \mu \mathrm{M}$ has been shown to promote osteoblastic differentiation in vitro [27,33-35], 2) there is a dynamic exchange of interstitial fluids in vivo, flow rate in pig bones was estimated to be $7.5-21.3 \mathrm{ml} / \mathrm{min} / 100 \mathrm{~g}$ [36] and, 3) $1 \mathrm{~h}$-set cement released almost half of the dosage in 1 day (preliminary study using a simvastatin solution of 2 $\mathrm{mM})$.

\subsection{Characterization of the handling and structural properties}

Pristine cement $(\mathrm{C}-\mathrm{XX})$ and simvastatin-loaded cement (s-C-XX) were characterized fresh (3 min after mixing the phases, C-3m and s-C-3m), set for $1 \mathrm{~h}(\mathrm{C}-1 \mathrm{~h}$ and s-C-1h) and set for $15 \mathrm{~h}(\mathrm{C}-15 \mathrm{~h}$ and s$\mathrm{C}-15 \mathrm{~h}$ ). Hereafter XX indicates the time between mixing and measurement. s-C-3m aimed to simulate a clinical scenario in which a fresh cement was applied. Cements set at two additional time points showed the release occurring from pre-set cements, where the two times were chosen in an attempt to correlate material microstructure to release profile, based on preliminary testing.

\section{a) Handling of fresh cement}

The cement paste, prepared without and with simvastatin in the liquid phase was evaluated in terms of cohesion, setting time and injectability. The cohesion of the cement paste was evaluated by injecting 
the paste 3 min after mixing the phases using a $2 \mathrm{~mm}$ aperture syringe (BD, ref. n. 309658, USA) into a PBS solution. After $1 \mathrm{~h}$ at $37^{\circ} \mathrm{C}$, the integrity of the paste in PBS was evaluated by visual inspection [37]. The initial and final setting times were determined by means of Gillmore needles after setting the cements in air ( $\left.\mathrm{T}=22 \pm 2{ }^{\circ} \mathrm{C}\right)$ [38]. Briefly, the assay consists in determining the time needed after the start of mixing in order not to create an indentation on the cement surface. The initial and final setting time refer to the use of low and high pressure tips, respectively. Duplicates were used to determine the cohesion of the paste and triplicates to evaluate the setting times.

Injectability of the cement pastes was evaluated using an experimental setup reproducing a minimallyinvasive procedure (Figure 1) by means of a universal testing machine (Shimadzu, AGS-X, Kyoto, Japan) with a $5 \mathrm{kN}$ load-cell (SSM-DAK-5000N, Shimadzu, Japan). The cement paste (prepared using $4 \mathrm{~g}$ of powder) was transferred into a $2 \mathrm{~mm}$ aperture syringe (BD, ref. $\mathrm{n}$. 309658, USA) connected to a stainless steel G13 needle (OptiMed, ref. n. 1384-1013, diameter of $2.4 \mathrm{~mm}$, length of $100 \mathrm{~mm}$, Germany). Extrusion started at half of the initial setting time (i.e. 3 min) [39]. The paste was injected into a foam [40] mimicking the cancellous bone structure at a cross-head speed of $15 \mathrm{~mm} / \mathrm{min}$ until the applied force reached $150 \mathrm{~N}$, corresponding to the established force that can be applied to a syringe by hand $[39,41]$. The foam used was a cellular rigid polyurethane foam (Sawbones ${ }^{\circledR}$, density of 0.12 $\mathrm{g} / \mathrm{cm}^{3}, 2.5 \times 2.5 \times 2.5 \mathrm{~cm}^{3}$; ref. n. 1522-09, USA), filled previously with a bone-marrow like substitute, i.e. 2.5 wt.\% carboxymethyl cellulose sodium salt [42] (CCS, ref. n. 419273, Sigma Aldrich, USA). The foam was placed into a 5-faces Teflon cube and was immersed into a beaker filled with phosphate buffered saline (PBS, ref. n. P4417, Sigma Aldrich, USA) used to mimic a physiological solution. The force applied to the syringe piston during injection (extrusion force) was monitored, and the average of this force between 10 and $30 \mathrm{~mm}$ of the piston's displacement was calculated. The percentage of paste injected was calculated using Equation 1.

\section{$\operatorname{Injectability}(\%)=\left(w_{i}-w_{a}\right) /\left(w_{i}-w_{e}\right) * 100 \quad$ Equation 1}

where $\mathrm{w}_{\mathrm{i}}$ is the weight of the cement filled syringe, $\mathrm{w}_{\mathrm{a}}$ is the weight of the syringe after injecting the paste, and $\mathrm{w}_{\mathrm{e}}$ is the weight of the empty syringe. The injectability tests were performed using triplicates. 
The spreading pattern of the injected cement paste was evaluated by means of micro-computed tomography ( $\mu \mathrm{CT}$, Skyscan 1072, Bruker, Kontich, Belgium) using the triplicates produced in the injectability test. Specimens were acquired using a source voltage of $80 \mathrm{kV}$, a current of $124 \mu \mathrm{A}$, a 0.5 $\mathrm{mm}$ aluminium filter, and an isotropic pixel size of $27 \mu \mathrm{m}^{2}$. Reconstruction of cross sections and 3D reconstructions were performed using software package NRecon and CTvox (SkyScan, Bruker, Kontich, Belgium). The reconstructed images were binarized to separate the cement from the foam and the background, using a global threshold. The diameter and sphericity of the injected cement was calculated using CTAn (SkyScan, Bruker, Kontich, Belgium). Sphericity ( $\Psi$ ) of an object is defined as the ratio of the surface area of a sphere with the same volume as the given object to the surface area of the object [43]. Sphericity was calculated as indicated in Equation 2.

$\Psi=\sqrt[3]{\pi}(6 V)^{\frac{2}{3}} / S \quad$ Equation 2

where $\mathrm{V}$ is the object volume and $\mathrm{S}$ is the object surface area.

\section{b) Structural properties of fresh and set cements}

The samples were moulded in air at $22 \pm 2{ }^{\circ} \mathrm{C}$, and some samples were further set in $100 \%$ relative humidity (sealed box containing water) at $37^{\circ} \mathrm{C}$ for $1 \mathrm{~h}$ and $15 \mathrm{~h}$. Discs with a diameter of $12 \mathrm{~mm}$ and height of $2 \mathrm{~mm}$ were used for evaluating the morphology, while cylinders with diameter of $6 \mathrm{~mm}$ and height of $12 \mathrm{~mm}$ were prepared for pore entrance size distribution analysis and compressive strength determination. To evaluate materials $3 \mathrm{~min}, 1 \mathrm{~h}$ and $15 \mathrm{~h}$ after mixing the phases, the reaction was stopped by immersing the samples in liquid nitrogen for 2-5 min and further drying them in a freeze dryer (ScanVac Cool Safe, LaboGene, Lynge, Denmark) [44]. The evolution of the crystalline phases was evaluated in situ using samples moulded in the X-ray diffraction (XRD) sample holder (diameter of $26 \mathrm{~mm}$ and height of $1 \mathrm{~mm}$ ) by XRD (Bruker D8 Advanced, USA), using a Bragg-Brentano thetatheta setup, $\mathrm{Cu}-\mathrm{K} \alpha$ radiation and a nickel filter. Scanning was performed with a step size of $0.03^{\circ}$ per step, $0.1 \mathrm{~s}$ per step and a rotation speed of $80 \mathrm{rpm}$ between $10^{\circ}$ and $40^{\circ}$ (total time of approximately $1.5 \mathrm{~min})$. The diffraction patterns were compared with reference patterns found in the PDF4+ database by the international centre for diffraction data (ICDD), and were: brushite $\left(\mathrm{CaHPO}_{4} 2 \mathrm{H}_{2} \mathrm{O}\right)$ from PDF\# 
04-013-3344 [45], $\beta$-TCP $\left(\beta-\mathrm{Ca}_{3}\left(\mathrm{PO}_{4}\right)_{2}\right)$ from PDF\# 04-008-8714 [46], MCPM $\left(\mathrm{Ca}\left(\mathrm{H} \beta-\mathrm{PO}_{4}\right)_{2} \mathrm{H}_{2} \mathrm{O}\right)$ from PDF\# 04-011-3010 [47], and $\beta$-calcium pyrophosphate (CPP, $\left.\mathrm{Ca}_{2} \mathrm{P}_{2} \mathrm{O}_{7}\right)$ from PDF\# 04-009-3876 $[48]$.

To evaluate the microstructure the samples were coated with a mixture of gold and palladium and observed with a scanning electron microscope (SEM, Zeiss Leo 1550, Germany). Entrance pore size distribution, total porosity, and tortuosity factor were measured by mercury intrusion porosimetry (MIP, Autopore IV 9500, Micromeritics, USA) using 4 different cylindrical samples in the holder in a single measurement. The tortuosity factor has an inverse relationship with the diffusion efficiency of fluids through a porous matrix (the lower the tortuosity factor, higher the efficiency) [49]. The compressive strength was only measured for the completely set samples, C- $15 \mathrm{~h}$ and s-C- $15 \mathrm{~h}$. The samples were loaded in a universal testing machine (Schimadzu, AGS-X, Japan) equipped with a loadcell of $5 \mathrm{kN}$ at a cross-head speed of $1 \mathrm{~mm} / \mathrm{min}$. Seventeen specimens of each group were tested.

\subsection{Drug release study}

The drug release pattern of s-C-3m, s-C- $1 \mathrm{~h}$ and s-C- $15 \mathrm{~h}$ was evaluated using discs (diameter of 12 $\mathrm{mm}$, height of $2 \mathrm{~mm}$ ), which were placed into $50 \mathrm{ml}$ PBS containers on a rocking platform (Heidolph, Duomax 1030) at $37^{\circ} \mathrm{C}$. Controls were C-3m, C-1h and C-15h, along with a simvastatin dilution. At different time points (hourly for the first $8 \mathrm{~h}$ and twice a day for the following 4 days) a $1 \mathrm{ml}$ aliquot was removed from each container and replaced by $1 \mathrm{ml}$ of fresh PBS (sampling process). The simvastatin concentration in the aliquots was monitored in a UV-spectrophotometer (Shimadzu, Japan; $\lambda=238 \mathrm{~nm}$ ) using a standard curve. Samples from fresh cement were centrifuged for $5 \mathrm{~min}$ at 1000 rpm before absorbance reading since the cement released some particles into the media. The data was corrected taking into account the discrete dilution at every sampling and the background of the counterpart samples (PBS signal was subtracted from samples of simvastatin alone, and C-xx signal was subtracted from s-C-xx samples). The data was not corrected for degradation since simvastatin was stable within time and $\mathrm{pH}$ (data not shown). Triplicates of each group were used and the assay was performed three times. 
Drug release patterns may be evaluated through several mathematical models (e.g. zero order, first order, Hixson-Crowell, Weibull, Higuchi, Baker-Lonsdale, Korsmeyer-Peppas and Hopfenberg models [50]) to identify underlying mechanisms involved in the release phenomena. In this work, the Korsmeyer Peppas (KP) model was selected due to its versatility and ability to provide insights regarding the limiting drug release mechanism. The drug concentration released was correlated to Equation 3, where $M_{t}$ is the drug amount at time t, $M_{\infty}$ is the maximum amount released from the material in the experimental conditions, $k$ is a constant incorporating characteristics of the matrix and of the drug, and $n$ is the diffusional exponent that is indicative of the limiting transport mechanism $[50,51]$

$M_{t} / M_{\infty}=k t^{n} \quad$ Equation 3

Based on the concentration versus time data, $M_{t} / M_{\infty}$ was calculated for each specimen and averaged for each condition. Modeling was performed using MatLab (The Mathworks, USA) taking into account the inverse of the standard deviation of $M_{t} / M_{\infty}$ as weights for modeling. The parameters extracted from Matlab were $\mathrm{k}, \mathrm{n}$ and the coefficient of determination, $\mathrm{R}^{2}$.

\subsection{Statistics}

Statistical analysis was done using IBM SPSS Statistics 19 software (IBM, USA). An independent samples t-test was used to analyse the differences among $\mathrm{C}$ and s-C groups. A significance level of $\alpha=$ 0.05 was used for all tests.

\section{Results}

\subsection{Handling of fresh cement}

Both $\mathrm{C}$ and s-C kept their integrity after being injected into an aqueous solution 3 min after mixing the phases (Figure 2). For both $\mathrm{C}$ and $\mathrm{s}-\mathrm{C}$, the initial setting times $(\mathrm{p}=0.769)$ and final setting times $(\mathrm{p}=$ 0.807) were around 7 and 14 min, respectively (Table 1).

The extrusion force and the amount of paste injected when extruding the paste through a G13 needle into a cancellous bone-like foam filled with a bone marrow-like showed no significant differences $(\mathrm{p}=$ 
0.235 for extrusion force and $\mathrm{p}=0.317$ for amount injected, respectively) between $\mathrm{C}$ and $\mathrm{s}-\mathrm{C}$ (Figure

3). The $\mu \mathrm{CT}$ visualization showed that the pristine cement had set in a spherical geometry and did not reach the borders of the box (Figure 4). The diameter of the cement ball was $15.6 \pm 1.2 \mathrm{~mm}$ and its sphericity was $0.841 \pm 0.001$.

\subsection{Structural properties of fresh and set cement}

The evolution of the crystalline phases with time, as determined by XRD, is shown in Figures 5 a and b. At each time point, the phases observed and the intensity of the peaks were similar for both $\mathrm{C}$ and s-

C. The powder phases mainly consisted of $\beta$-TCP and MCPM, and CPP and monetite were found as impurities present in each reagent, respectively. The main crystalline phases of the fresh cements $(\mathrm{C}$ $3 \mathrm{~m}$ and $\mathrm{s}-\mathrm{C}-3 \mathrm{~m}$ ) were $\beta$-TCP and MCPM, whereas brushite was only present in small amounts. $1 \mathrm{~h}$ after mixing the phases (C-1h and s-C-1h), the main crystalline phase present was brushite, and none of the initial reagents was detected anymore. Brushite was also the main phase in $\mathrm{C}-15 \mathrm{~h}$ and s-C-15h.

The morphology of the fresh cements (C-3m, s-C-3m) was heterogeneous, with some areas showing a glass-like structure (Figure $6 \mathrm{~b}$ ) while other areas presented a mixture of elongated precipitated crystals and round particles (Figure 6 a). Both morphologies were present in C-3min and s-C-3min. After $1 \mathrm{~h}$ an important evolution of the morphology was observed. Both $\mathrm{C}-1 \mathrm{~h}$ and s-C-1h were constituted by rhombohedrical crystals between 0.5 and $5 \mu \mathrm{m}$ randomly distributed along the surface, the crystal size of $\mathrm{C}$ being slightly smaller than that of s-C (Figure $6 \mathrm{c}$ and d). The morphologies did not experience any important changes after $15 \mathrm{~h}$, the crystal size of $\mathrm{C}-15 \mathrm{~h}$ remaining slightly smaller than that of s-C-15h) (Figure $6 \mathrm{e}$ and $\mathrm{f}$ ).

The pore entrance size distribution (Figure 7 a) revealed that cements set for $1 \mathrm{~h}(\mathrm{C}-1 \mathrm{~h}$ and s-C-1h) and cements set for $15 \mathrm{~h}(\mathrm{C}-15 \mathrm{~h}$ and s-C-15h) had a similar distribution of pore entrance sizes centred around $300 \mathrm{~nm}$. However, fresh cements $(\mathrm{C}-3 \mathrm{~m}$ and $\mathrm{s}-\mathrm{C}-3 \mathrm{~m})$ had wider pore entrance size distributions and it was observed that simvastatin shifted the pore size entrance from $270 \mathrm{~nm}$ to 440 $\mathrm{nm}$. The tortuosity factor (has an inverse relationship with the diffusion of fluids through a matrix) followed an opposite trend to the porosity (Figure $7 \mathrm{~b}$ ). For both $\mathrm{C}$ and $\mathrm{s}-\mathrm{C}$ a decrease in porosity and 
an increase in tortuosity factor was observed with time left to set, these changes being more pronounced for s-C, particularly from the fresh (s-C-3m) to the 1 h-set form (s-C-1h). All set samples (set for $1 \mathrm{~h}$ and $15 \mathrm{~h}$ ) had a similar porosity and tortuosity factor regardless of the presence of simvastatin.

The presence of simvastatin decreased significantly $(\mathrm{p}=0.024)$ the compressive strength of $\mathrm{C}$ from $32.7 \pm 4.6$ to $28.7 \pm 5.0 \mathrm{MPa}$ for s-C samples set in $100 \%$ relative humidity for $15 \mathrm{~h}$ (Figure 8 ).

\subsection{Drug release}

The release profiles of all simvastatin-loaded materials are reported in Figure 9a. s-C-3m presented a burst release of simvastatin and showed the fastest release profile of all for the first $24 \mathrm{~h}$, during which $56.1 \pm 4.0 \%$ of the drug loaded was released, corresponding to $75.3 \pm 5.5 \mu \mathrm{g}$. The drug release of s-C$1 \mathrm{~h}$ also presented a burst release for the first $24 \mathrm{~h}$, although less pronounced than s-C-3m. The amount of simvastatin released for s-C- $1 \mathrm{~h}$ was $42.8 \pm 2.7 \%$, corresponding to $57.5 \pm 3.6 \mu \mathrm{g}$. s-C- $15 \mathrm{~h}$ released simvastatin in a sustained manner, reaching $14.4 \pm 1.8 \%$ of simvastatin released after $24 \mathrm{~h}$, corresponding to $19.4 \pm 2.4 \mu \mathrm{g}$. Only s-C- $15 \mathrm{~h}$ released simvastatin during the entire study period (4.5 days), whereas s-C-3m and s-C-1h reached a stationary state after 1.5 days.

The amount of drug released from each cement group was fitted to the KP equation (Figure $9 \mathrm{~b}$, Equation 3). The outcome of fitting (Table 2) showed that only the s-C-15h provided an excellent goodness of fit $\left(\mathrm{R}^{2}>0.95\right)$ and the $\mathrm{n}$ parameter indicated an anomalous (non-Fickian) transport $(0.45<$ $\mathrm{n}<1.00)$ [51,52]. In contrast, s-C-1h gave a good goodness of fit $\left(0.90<\mathrm{R}^{2}<0.95\right)$ but did not allow for drawing any conclusion on the limiting mechanism of release as the parameter (n) did not correspond to any known range according to the KP assumptions. The limiting mechanism of release for $\mathrm{s}-\mathrm{C}-3 \mathrm{~min}$ could not be determined either since it gave a too low goodness of fit $\left(\mathrm{R}^{2}<0.90\right)$.

\section{Discussion}

CPCs are outstanding materials compared to other ceramics for bone regeneration thanks to their injectability, potential as drug delivery systems and their similarity with the mineral phase of bone [4] 
[7]. Clinically, CPCs can locally deliver drugs when applied at the target site either by minimally invasive surgery or as a pre-set block. This provides a clear benefit as compared to its systemic administration, including enhanced and immediate availability at the target site and reduction of side effects [7].

Therefore, an in-depth characterization and understanding of the drug release pattern of the cements is of high interest to ensure that the local drug concentration quickly reaches the therapeutic window and remains in that range during the treatment duration needed. Structural properties such as microstructure, porosity and tortuosity play a critical role on the drug diffusion from the bulk material and are therefore linked to the release profiles recorded [21]. In this work, the structural properties at different reaction points as well as the drug release patterns of the cement were monitored. The fresh cement (s-C-3m) mimicked a clinical scenario in which the paste was injected or moulded in situ; s-C$1 \mathrm{~h}$ and s-C-15h allowed linking the material structure to the drug release profile using pre-set cements, which can be considered as pre-set blocks [4].

The initial and final setting times (Table 1) were within the ranges recommended for clinical applications (i.e. 4-8 min for the initial setting time, and 10-15 min for the final setting time) [53]. The cement pastes had a good cohesion at 3 min (Figure 2), this time being shorter than the initial setting time and therefore fulfilling the clinical demands [54]. Although the good cohesion exhibited shortly after mixing is crucial to evaluate the drug release pattern of fresh cements, the fresh cements (s-C$3 \mathrm{~m})$ released some particles and for this reason the aliquots had to be centrifuged before measuring the simvastatin concentration. It should be noted that in the conditions used to evaluate the drug release (i.e. a piece of cement immersed in a large volume of PBS, maintained in constant agitation), the cement was more exposed to the environment than in a real situation, which increased the release of particles.

The injectability was tested using a model close to a clinical situation, using a G13 cannula to inject the material into a cancellous bone-like foam filled with a bone marrow-like substitute [40]. The materials were fully injectable, with a clinically relevant extrusion force (Figure 3) [39,41] and did not show signs of filter pressing or phase separation. The injected cement exhibited a uniform ball-like 
shape (Figure 4), and while there is no literature data on specific sphericity values of CPC cements, it could be assumed that this shape would be beneficial in terms of a reduced risk for leakage in clinical applications such as vertebroplasty [55], as has been the hypothesis for PMMA cements [40,56,57]. This was confirmed by the non-arrival of the cement to the border of the box in all samples, in combination with the relatively low injection forces [40,56,57].

The SEM observations (Figure 6) correlated well with the crystalline phases determined by XRD (Figure 5) for all times studied. Whereas at 3 min round particles of the reagents ( $\beta$-TCP and MPCM) could still be observed, most of the reagents had been transformed into brushite after $1 \mathrm{~h}$. The morphology of brushite crystals slightly evolved between $1 \mathrm{~h}$ to $15 \mathrm{~h}$, which was corroborated by the total porosity values and the tortuosity factor (Figure $7 \mathrm{~b}$ ).

In drug delivery systems, the drug should not compromise the physical properties of the carrier, and the carrier should not alter the active principle of the drug [7]. Brushite cements have a high ionic concentration and an acidic setting reaction, properties that could reduce or inhibit the action of certain drugs [7]. Nevertheless, a previous study concluded that the therapeutic action of simvastatin was not altered after being released by a brushite cement [23], which could be partially explained by the stability of simvastatin in acidic pHs [31].

In the current work, the unaltered handling properties of the paste: cohesion (Figure 2), setting times (Table 1) and injectability (Figure 3) suggested that the addition of simvastatin did not modify the workability of the paste, as suggested elsewhere [23]. Although simvastatin did not prevent the transformation of the reagents into rhombohedric crystals of brushite (Figure 5), it did however enhance the crystal growth at $1 \mathrm{~h}$ and $15 \mathrm{~h}$ (Figure 6). The larger crystals size of s-C could be ascribed to the higher buffering capacity of the simvastatin solution in comparison to the distilled water used in C, allowing a slower solubilisation-precipitation process and thus a further growth of the crystals. The larger crystals of s-C left larger open pores in the matrix in comparison with $\mathrm{C}$ (Figure 7), factors that may have caused the drop in the mechanical properties at 15h [58] (Figure 8). The alteration of the compressive strength by simvastatin was however in disagreement with a previous work performed with premixed cements [23]. 
Interestingly, s-C-3m showed the highest porosity and the lowest tortuosity factor of all (Figure 7b). This indicated that although at short times there were interconnected opened pores, the entanglement of precipitating brushite crystals closed these pores after $1 \mathrm{~h}$, reducing the porosity and increasing the tortuosity factor to a similar level to the rest of the groups. This was confirmed by SEM, set cements (both set for $1 \mathrm{~h}$ and $15 \mathrm{~h}$ ) showed a network of precipitated crystals on their surface whereas few precipitated crystals were observed in fresh cements (Figure 6).

The release pattern depended on the time elapsed from cement preparation until immersion in the release media, with good correlation with the tortuosity and SEM results. The low tortuosity of s-C$3 \mathrm{~m}$ (Figure $7 \mathrm{~b}$ ) allowed for an initial burst release, whereas the higher tortuosity of s-C-15h caused a sustained release over time. s-C-1h showed an initial burst release although it presented a tortuosity and morphology closer to s-C-15h than s-C-3m. This suggests that the parts of the cement still not set at $1 \mathrm{~h}$, i.e. unreacted reagents and water-filled pores, continue to give a strong contribution to drug release facilitation at this time point. The drug release patterns resulted in approximately a double amount of drug released from s-C-3m and s-C-1h compared to s-C-15h at 4.5 days (Figure 9 a). This large difference in the percentage released could not be observed in a previous study in which a drug (doxycycline hyclate) was released from apatite cements set for $1 \mathrm{~h}$ and 7 days [10]. This could be due to several factors, for example, the time the cements were set for, the dissimilar matrices of the cements (brushite vs. apatite), the total porosity and range of pore entry sizes of the materials, the drug-carrier interactions and the dimensions of the specimens [59].

In a previous study using premixed brushite cement as carrier of simvastatin (a similar amount, of 0.25 mg simvastatin/g cement) [23] a slow drug release was observed and almost all drug was released after 7 days. The drug release pattern for the premixed brushite cement was similar to the one observed for the aqueous brushite cement s-C-15h, which could indicate a high tortuosity factor of the premixed cement. However, initially, the structure of a premixed brushite cement should be similar to that of a fresh cement, it would only start setting after the exchange of glycerol by water takes place. Therefore, it could be speculated that the slow drug release was caused by the presence of glycerol in the matrix, a viscous solution that could slow down the diffusion of the drug. The higher amount of drug released 
in the study using premixed brushite could be further explained by the different experimental conditions (e.g. sample immersed in $5 \mathrm{ml}$ rather than $50 \mathrm{ml}$, different material matrix of the material, etc.). In particular, in the premixed cement study the entire solution was exchanged by fresh PBS, whereas in the current study only a small fraction of the solution was exchanged.

The drug release kinetics were modeled using the Korsmeyer-Peppas (KP) model. The diffusional exponent $\mathrm{n}$ indicated that the release mechanism from s-C-15h was anomalous (non-Fickian). For the 1 h-set cement (s-C-1h), the good fitting of the release profile to the KP equation (Table 2) but impossibility to conclude on the controlling release mechanism as the $\mathrm{n}$ parameter was out of range may be explained by the evolution of the cement matrix with time. The same reason could explain the low goodness of fit of the $3 \mathrm{~min}$-set cement (s-C-3min). This was in accordance with a previous work in which the matrix of apatite cement, which is known to react slowly, was shown to be still evolving after $1 \mathrm{~h} \mathrm{[10].}$

The $\mathrm{k}$ constant, which provides information about the cement matrix, is proportional to the square root of the effective coefficient of diffusion $\mathrm{D}$, the latter being inversely proportional to the tortuosity of the matrix [60]. Assuming the release mechanism of fresh (s-C-3m) and $1 \mathrm{~h}$-set cements (s-C-1h) is the same as the $15 \mathrm{~h}$-set cement ( $\mathrm{s}-\mathrm{C}-15 \mathrm{~h}$ ), i.e. $\mathrm{n}=0.77$, the variation of $\mathrm{k}$ as a function of time can be derived from the data (Figure $9 \mathrm{~b}$ ). The initial $\mathrm{k}$ value for each cement $\left(\mathrm{k}_{3 \min }>\mathrm{k}_{1 \mathrm{~h}}>\mathrm{k}_{15 \mathrm{~h}}\right)$ followed an inverse correlation with the tortuosity factor $(\mathrm{TF})$ results from $\mathrm{MIP}\left(\mathrm{TF}_{3 \min }<\mathrm{TF}_{\mathrm{hh}}<\mathrm{TF}_{15 \mathrm{~h}}\right)($ Figure 7 b), indicating that the cements set for a longer time had a higher tortuosity. Similarly, the matrix of the fresh cement (s-C-3m) showed an increasing tortuosity with time, i.e. a decreasing $\mathrm{k}$ factor. In contrast, the $1 \mathrm{~h}$-set cement (s-C-1h) slightly evolved with time. Interestingly, the three s-C materials reached a final common $\mathrm{k}$ value, confirming that the matrix of all simvastatin-loaded materials was similar. The increase in tortuosity observed through modeling may be linked again to the progressive entanglement of the brushitic crystals of the setting matrix. Accordingly, fresh cements (s-C-3m) presented lower tortuosity and released simvastatin faster than the cements set for $15 \mathrm{~h}$ (s-C-15h). 
No tests were performed to confirm the final amount of drug remaining in the cement after drug release. However, since a solution of simvastatin was used to load the drug into the brushite cement, any drug loss during sample preparation was considered highly unlikely.

The theoretical total amount of simvastatin incorporated into the cements was $134 \mu \mathrm{g} / \mathrm{sample}$. Using the range of flow rates for cortical and trabecular bone in pig determined by Nekano et al. [36], i.e. 7.5 $-21.3 \mathrm{ml} / \mathrm{min} / 100 \mathrm{~g}$, a sample (approx. $0.5 \mathrm{~g}$ ) would be diluted by $54-153 \mathrm{ml}$ of fluid after $24 \mathrm{~h}$. This would give rise to a dynamic concentration of simvastatin within the micromolar range, which could be expected to stimulate osteoblastic cells [27,33-35]. The incorporation of simvastatin in brushite cement can therefore be expected to increase the effectiveness of the non-invasive treatment, this remaining to be evaluated in future studies.

\section{Conclusions}

This work characterized the handling, structural and physico-chemical properties and the drug release patterns of brushite cements fresh ( $3 \mathrm{~min}$ ) and set for different times ( $1 \mathrm{~h}$ and $15 \mathrm{~h})$. The addition of simvastatin did not significantly alter the handling properties of the pristine cement paste nor the crystalline phases, porosity and tortuosity of $15 \mathrm{~h}$-set cements. Simvastatin however caused an increase of the crystal size and decreased the mechanical properties of $15 \mathrm{~h}$-set cements. The release of simvastatin showed that fresh cements and cements set for $1 \mathrm{~h}$ burst-released simvastatin during $8 \mathrm{~h}$, whereas cements set for $15 \mathrm{~h}$ released it in a sustained manner. The cements set for $1 \mathrm{~h}$ and $15 \mathrm{~h}$ allowed fitting a KP equation to model the drug release, although while $15 \mathrm{~h}$-set cement revealed an anomalous release transport, the release mechanism could not be concluded for $1 \mathrm{~h}$-set cement. The evolution of the $\mathrm{k}$ parameter of fresh cements showed that the tortuosity increased with time, whereas it slightly changed for cements set for $1 \mathrm{~h}$. All cements converged to a common k value at 4.5 days, indication of their similar matrix. This study concluded that the setting of a material reduces the accessibility of the release media to the material, and thus hinders drug release. 


\section{Acknowledgements}

This work was co-funded by Marie Curie Actions FP7-PEOPLE-2011-COFUND (GROWTH 291795) via the VINNOVA programme Mobility for Growth (project n. 2013-01260), the Swedish Foundation for International Cooperation in Research and Higher Education (STINT, project n. IG2011-2047), Lars Hiertas Minne Foundation (project n. FO2014-0334) and Ollie \& Elof Ericssons Stifelse för Vetenskaplig Forskning. Part of this work was performed at the BioMat facility /Science for Life Laboratory at Uppsala University. 


\section{References}

[1] R.Z. LeGeros, A. Chohayeb, A. Shulman, Apatitic calcium phosphates: possible dental restorative materials, J. Dent. Res. 61 (1982) 343-347.

[2] W. Brown, L. Chow, A new calcium phosphate setting cement, J. Dent. Res. 62 (1983) 672.

[3] R.Z. Legeros, Biodegradation and bioresorption of calcium phosphate ceramics, Clin. Mater. 14 (1993) 65-88.

[4] M.P. Ginebra, M. Espanol, E.B. Montufar, R.A. Perez, G. Mestres, New processing approaches in calcium phosphate cements and their applications in regenerative medicine, Acta Biomater. 6 (2010) 2863-73.

[5] M.P. Ginebra, Calcium Phosphate bone cements, in: S. Deb (Ed.), Orthop. Bone Cem., Woodhead Publishing Limited, Cambridge, 2008: pp. 206-230.

[6] M.P. Ginebra, E. Fernandez, M.G. Boltong, O. Bermudez, J.A. Planell, F.C.M. Driessens, Compliance of an apatitic calcium phosphate cement with the short- term clinical requirements in bone surgery, orthopaedics and dentistry, Clin. Mater. 17 (1994) 99-104.

[7] M.P. Ginebra, C. Canal, M. Espanol, D. Pastorino, E.B. Montufar, Calcium phosphate cements as drug delivery materials, Adv. Drug Deliv. Rev. 64 (2012) 1090-110.

[8] M. Bohner, J. Lemaitre, H.P. Merkle, B. Gander, Control of gentamicin release from a calcium phosphate cement by admixed poly(acrylic acid), J. Pharm. Sci. 89 (2000) 1262-70.

[9] H.P. Stallmann, C. Faber, A.L.J.J. Bronckers, A. V Nieuw Amerongen, P.I.J.M. Wuisman, In vitro gentamicin release from commercially available calcium-phosphate bone substitutes influence of carrier type on duration of the release profile, BMC Musculoskelet. Disord. 7 (2006) 18.

[10] C. Canal, D. Pastorino, G. Mestres, P. Schuler, M.P. Ginebra, Relevance of microstructure for the early antibiotic release of fresh and pre-set calcium phosphate cements, Acta Biomater. 9 (2013) 8403-12.

[11] M. Otsuka, Y. Nakahigashi, Y. Matsuda, J.L. Fox, W.I. Higuchi, Y. Sugiyama, A novel skeletal drug delivery system using self-setting calcium phosphate cement VIII: the relationship between in vitro and in vivo drug release from indomethacin-containing cement, $\mathrm{J}$. Control. Release. 43 (1997) 115-122.

[12] M. Otsuka, K. Yoneoka, Y. Matsuda, J.L. Fox, W.I. Higuchi, Y. Sugiyama, Oestradiol release from self-setting apatitic bone cement responsive to plasma-calcium level in ovariectomized rats, and its physicochemical mechanism, J. Pharm. Pharmacol. 49 (1997) 1182-8.

[13] M. Otsuka, Y. Nakahigashi, Y. Matsuda, J.L. Fox, W.I. Higuchi, Y. Sugiyama, Effect of geometrical cement size on in vitro and in vivo indomethacin release from self-setting apatite cement, J. Control. Release. 52 (1998) 281-9.

[14] M. Otsuka, Y. Matsuda, A.A. Baig, A. Chhettry, W.I. Higuchi, Calcium-level responsive controlled drug delivery from implant dosage forms to treat osteoporosis in an animal model, Adv. Drug Deliv. Rev. 42 (2000) 249-58. 
[15] M. Otsuka, H. Nakagawa, A. Ito, W.I. Higuchi, Effect of geometrical structure on drug release rate of a three-dimensionally perforated porous apatite/collagen composite cement, 99 (2010) 286-292.

[16] T. Suzuki, K. Arai, H. Goto, M. Hanano, J. Watanabe, K. Tomono, Dissolution tests for selfsetting calcium phosphate cement-containing nifedipine, Chem. Pharm. Bull. (Tokyo). 50 (2002) 741-3.

[17] A.M. Young, P.Y.J. Ng, U. Gbureck, S.N. Nazhat, J.E. Barralet, M.P. Hofmann, Characterization of chlorhexidine-releasing, fast-setting, brushite bone cements, Acta Biomater. 4 (2008) 1081-8.

[18] M. Bohner, J. Lemaître, P. Van Landuyt, P.Y. Zambelli, H.P. Merkle, B. Gander, Gentamicinloaded hydraulic calcium phosphate bone cement as antibiotic delivery system, J. Pharm. Sci. 86 (1997) 565-72.

[19] U. Gbureck, E. Vorndran, J.E. Barralet, Modeling vancomycin release kinetics from microporous calcium phosphate ceramics comparing static and dynamic immersion conditions, Acta Biomater. 4 (2008) 1480-6.

[20] S. Girod Fullana, H. Ternet, M. Freche, J.L. Lacout, F. Rodriguez, Controlled release properties and final macroporosity of a pectin microspheres-calcium phosphate composite bone cement, Acta Biomater. 6 (2010) 2294-300.

[21] S. Hesaraki, R. Nemati, Cephalexin-loaded injectable macroporous calcium phosphate bone cement, J. Biomed. Mater. Res. B. Appl. Biomater. 89 (2009) 342-52.

[22] F. Tamimi, J. Torres, R. Bettini, F. Ruggera, C. Rueda, M. López-Ponce, et al., Doxycycline sustained release from brushite cements for the treatment of periodontal diseases, J. Biomed. Mater. Res. A. 85 (2008) 707-14.

[23] M. Montazerolghaem, H. Engqvist, M. Karlsson Ott, Sustained release of simvastatin from premixed injectable calcium phosphate cement, J Biomed Mat Res A. 102 (2014) 340-347.

[24] J.I. Germershausen, V.M. Hunt, R.G. Bostedor, P.J. Bailey, J.D. Karkas, A.W. Alberts, Tissue selectivity of the cholesterol-lowering agents lovastatin, simvastatin and pravastatin in rats in vivo, Biochem. Biophys. Res. Commun. 158 (1989) 667-75.

[25] B. Skoglund, C. Forslund, P. Aspenberg, Simvastatin improves fracture healing in mice, J. Bone Miner. Res. 17 (2002) 2004-8.

[26] G. Mundy, Stimulation of Bone Formation in Vitro and in Rodents by Statins, Science (80-. ). 286 (1999) 1946-1949.

[27] T. Maeda, A. Matsunuma, T. Kawane, N. Horiuchi, Simvastatin promotes osteoblast differentiation and mineralization in MC3T3-E1 cells, Biochem. Biophys. Res. Commun. 280 (2001) 874-7.

[28] M. Bohner, J. Lemaitre, T.A. Ring, Effects of sulfate, pyrophosphate, and citrate ions on the physicochemical properties of cements made of beta-tricalcium phosphate-phosphoric acidwater mixtures, J. Am. Ceram. 79 (1996) 1427-1434. 
[29] J. Engstrand, C. Persson, H. Engqvist, The effect of composition on mechanical properties of brushite cements, J. Mech. Behav. Biomed. Mater. 29 (2014) 81-90.

[30] F. Ungaro, C. Giovino, O. Catanzano, A. Miro, A. Mele, F. Quaglia, et al., Use of cyclodextrins as solubilizing agents for simvastatin: effect of hydroxypropyl- $\beta$-cyclodextrin on lactone/hydroxyacid aqueous equilibrium, Int. J. Pharm. 404 (2011) 49-56.

[31] M. Yoshinari, K. Matsuzaka, S. Hashimoto, K. Ishihara, T. Inoue, Y. Oda, et al., Controlled release of simvastatin acid using cyclodextrin inclusion system, Dent. Mater. J. 26 (2007) 4516.

[32] W.H. Kaesemeyer, R.B. Caldwell, J. Huang, R.W. Caldwell, Pravastatin Sodium Activates Endothelial Nitric Oxide Synthase Independent of Its Cholesterol-Lowering Actions, 33 (1999) 234-241.

[33] R. Hwang, E.J. Lee, M.H. Kim, S. Li, Y. Jin, Y. Rhee, et al., Calcyclin, a Ca2+ Ion-binding Protein, Contributes to the Anabolic Effects of Simvastatin on Bone, J. Biol. Chem. 279 (2004) 21239-21247.

[34] P.Y. Chen, J.S. Sun, Y.H. Tsuang, M.H. Chen, P.W. Weng, F.H. Lin, Simvastatin promotes osteoblast viability and differentiation via Ras/Smad/Erk/BMP-2 signaling pathway, 30 (2010) 191-199.

[35] K.H. Baek, W.Y. Lee, K.W. Oh, H.J. Tae, J.M. Lee, E.J. Lee, et al., The effect of simvastatin on the proliferation and differentiation of human bone marrow stromal cells, J Korean Med Sci. (2005) 438-444.

[36] T. Nakano, J.R. Thompson, R.J. Christopherson, F.X. Aherne, Blood flow distribution in hind limb bones and joint cartilage from young growing pigs, Can. J. Vet. Res. 50 (1986) 96-100.

[37] E. Fernandez, M.G. Boltong, M.P. Ginebra, F.C.M. Driessens, Development of a method to measure the period of swelling of calcium phosphate cements, J. Mater. Sci. Lett. 15 (1996) $1004-1005$.

[38] UNE-EN ISO, Standard Test Method for Time of Setting of Hydraulic-Cement Paste by Gillmore. Designation: C 266-03, 2003.

[39] M. Bohner, G. Baroud, Injectability of calcium phosphate pastes, Biomaterials. 26 (2005) 1553-63.

[40] G. Baroud, M. Crookshank, M. Bohner, High-viscosity cement significantly enhances uniformity of cement filling in vertebroplasty: an experimental model and study on cement leakage, Spine (Phila. Pa. 1976). 31 (2006) 2562-2568.

[41] I. Khairoun, M.G. Boltong, F.C.M. Driessens, J.A. Planell, Some factors controlling the injectability of calcium phosphate bone cements, J. Mater. Sci. Mater. Med. 9 (1998) 425-428.

[42] J.D. Bryant, T. David, P.H. Gaskell, P.H. King, G. Lond, Rheology of bovine bone marrow, Proc. Inst. Mech. Eng. H. 203 (1989) 71-75.

[43] H. Wadell, Volume, shape, and roundness of quartz particles, J. Geol. 43 (1935) 250-280. 
[44] E. Fernandez, M.P. Ginebra, M.G. Boltong, F.C.M. Driessens, J. Ginebra, E.A.P. De Maeyer, et al., Kinetic study of the setting reaction of a calcium phosphate bone cement, J. Biomed. Mater. Res. 32 (1996) 367-374.

[45] N.A. Curry, D.W. Jones, Crystal structure of brushite, calcium hydrogen orthophosphate dihydrate: a neutron-diffraction investigation, J Chem Soc. (1971) 3725-3729.

[46] B. Dickens, L.W. Schroeder, Crystallographic studies of the role of Mg as a stabilizing impurity in b-Ca3(PO4)2. I. The Crystal structure of pure b-Ca3(PO4)2, J Solid State Chem. 10 (1974) 232-248.

[47] L.W. Schroeder, E. Prince, B. Dickens, Hydrogen bonding in $\mathrm{Ca}(\mathrm{H} 2 \mathrm{PO} 4) 2 . \mathrm{H} 20$ as determined by neutron diffraction, Acta Crystallogr. B31 (1975) 9-12.

[48] S. Boudin, A. Grandin, M.M. Borel, A. Leclaire, B. Raveau, Redetermination of the $\beta$ Ca2P2O7 structure, Acta Crystallogr. Sect. C Cryst. Struct. Commun. 49 (1993) 2062-2064.

[49] J.M.P.Q. Delgado, A simple experimental technique to measure tortuosity in packed beds, Can. J. Chem. Eng. 84 (2006) 651-655.

[50] P. Costa, J.M. Sousa Lobo, Modeling and comparison of dissolution profiles, Eur. J. Pharm. Sci. 13 (2001) 123-33.

[51] P.L. Ritger, N.A. Peppas, A simple equation for description of solute release I. Fickian and non-fickian release from non-swellable devices in the form of slabs, spheres, cylinders or discs, J. Control. Release. 5 (1987) 23-36.

[52] J. Siepmann, N.A. Peppas, Higuchi equation: derivation, applications, use and misuse, Int. J. Pharm. 418 (2011) 6-12.

[53] M.-P. Ginebra, E. Fernández, M. Boltong, J.A. Planell, O. Bermúdez, F. Driessens, Compliance of an apatitic calcium phosphate cements with some short-term clinical requirements in surgery, orthopaedics and dentistry, Clin. Mater. 17 (1994) 99-104.

[54] F.C.M. Driessens, J.A. Planell, M.G. Boltong, I. Khairoun, M.P. Ginebra, Osteotransductive bone cements, Proc. Inst. Mech. Eng. Part H J. Eng. Med. 212 (1998) 427-435.

[55] R. Schmidt, B. Cakir, T. Mattes, M. Wegener, W. Puhl, M. Richter, Cement leakage during vertebroplasty: an underestimated problem?, Eur. Spine J. 14 (2005) 466-73.

[56] M. Bohner, B. Gasser, G. Baroud, P. Heini, Theoretical and experimental model to describe the injection of a polymethylmethacrylate cement into a porous structure, Biomaterials. 24 (2003) 2721-2730.

[57] A. Bou-Francis, A. López, C. Persson, R.M. Hall, N. Kapur, Assessing cement injection behaviour in cancellous bone: an in vitro study using flow models, J. Biomater. Appl. 29 (2014) 582-94.

[58] M.P. Ginebra, F.C.M. Driessens, J.A. Planell, Effect of the particle size on the micro and nanostructural features of a calcium phosphate cement: a kinetic analysis, Biomaterials. 25 (2004) 3453-62. 
[59] J. Siepmann, H. Kranz, N. a Peppas, R. Bodmeier, Calculation of the required size and shape of hydroxypropyl methylcellulose matrices to achieve desired drug release profiles, Int. J. Pharm. 201 (2000) 151-64.

[60] K. Khanafer, K. Vafai, The role of porous media in biomedical engineering as related to magnetic resonance imaging and drug delivery, Heat Mass Transf. 42 (2006) 939-953. 
Table 1

Initial and final setting times of pristine and simvastatin-loaded brushite cement.

\begin{tabular}{lcc}
\hline & Pristine cement $(\mathrm{C})$ & Simvastatin-loaded cement $(\mathrm{s}-\mathrm{C})$ \\
\hline $\mathrm{t}_{1}(\mathrm{~min})$ & $6.7 \pm 1.0$ & $6.5 \pm 0.4$ \\
$\mathrm{t}_{\mathrm{F}}(\mathrm{min})$ & $13.6 \pm 2.1$ & $13.4 \pm 0.5$ \\
\hline
\end{tabular}

Table 2

Parameters obtained from Korsmeyer-Peppas modelling for cements fresh ( $3 \mathrm{~min}$ after mixing the phases) and set for $1 \mathrm{~h}$ and $15 \mathrm{~h}$.

\begin{tabular}{lccc}
\hline & \multicolumn{3}{c}{ Korsmeyer-Peppas model } \\
\cline { 2 - 4 } Material & $\mathrm{k}$ & $\mathrm{n}$ & $\mathrm{R}^{2}$ \\
\hline s-C-3 m & 0.8397 & 0.1918 & 0.7507 \\
s-C-1 h & 0.6008 & 0.4181 & 0.9463 \\
s-C-15 h & 0.3571 & 0.7674 & 0.9804 \\
\hline
\end{tabular}




\section{Figures}

Figure 1. Schematic figure of the setup used for evaluation of the injectability. CCS stands for carboxymethyl cellulose sodium salt.

Figure 2. Brushite cement injected with a syringe into an aqueous solution, 3 min after phases mixture. Cohesion evaluated $1 \mathrm{~h}$ after injection: a) pristine material, b) simvastatin-loaded material.

Figure 3. Injectability and extrusion force of pristine cement (C) and simvastatin-loaded cement (s-C).

Figure 4. $\mu \mathrm{CT}$ images showing a pristine cement injected, a) entire foam, b) coronal section of image (a) in which the foam (dark grey) is containing the cement (white).

Figure 5. Evolution of the crystal phases in situ. For a) pristine cement and b) simvastatin-loaded cement. The initial powder (P), fresh cement ( 3 min after mixing the phases), and cement set for $1 \mathrm{~h}$ and $15 \mathrm{~h}$ are displayed.

Figure 6. SEM images of pristine cement a) fresh ( 3 min after mixing the phases), c) set for $1 \mathrm{~h}$ and e) set for $15 \mathrm{~h}$; and simvastatin-loaded cement b) fresh ( 3 min after mixing the phases), d) set for $1 \mathrm{~h}$ and f) set for $15 \mathrm{~h}$. Images a and $\mathrm{b}$ are representative morphologies found in both pristine and simvastatinloaded cement.

Figure 7. a) Pore size distribution and b) total porosity and tortuosity factor of pristine cements (C) and simvastatin-loaded cements (s-C) evaluated fresh (3 min after mixing the phases) and set for $1 \mathrm{~h}$ and $15 \mathrm{~h}$.

Figure 8. Mechanical properties of pristine cement (C) and simvastatin-loaded cement (s-C) set for 15 h.

Figure 9. a) Release of simvastatin from simvastatin-loaded cements, fresh (3 min after mixing the phases) and set for $1 \mathrm{~h}$ and $15 \mathrm{~h}$ before immersing the samples in the release solution; b) $\mathrm{k}$ parameter vs. release time considering a fixed $n$ value of 0.77 . 


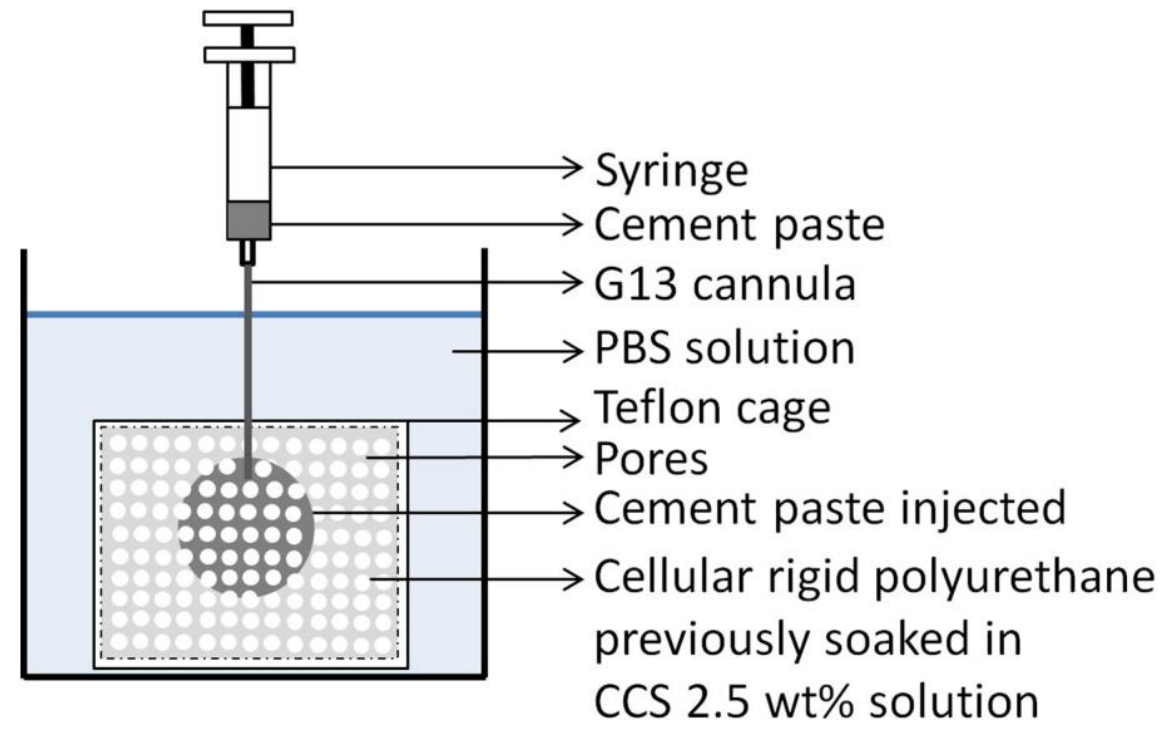

Fig. 1. Schematic figure of the setup used for evaluation of the injectability. CCS stands for carboxymethyl cellulose sodium salt. 


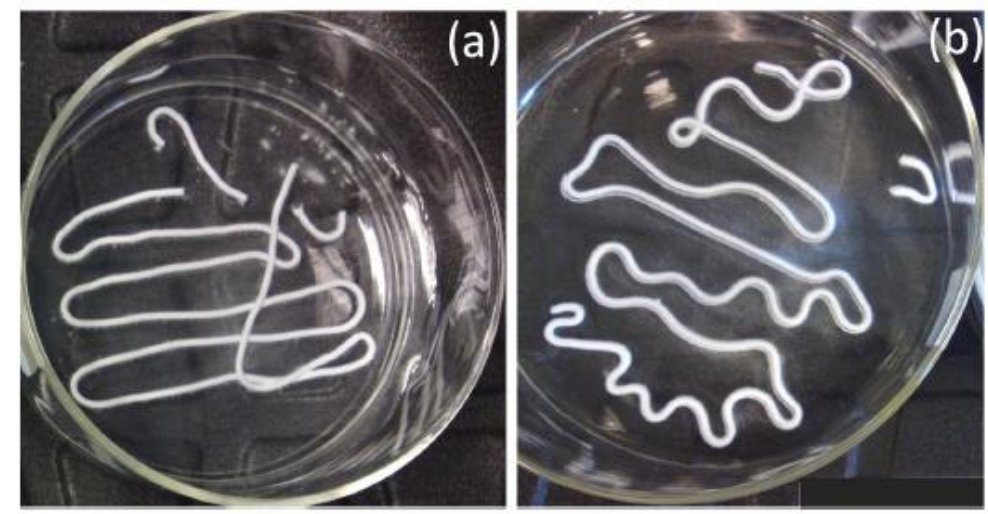

Fig 2. Brushite cement injected with a syringe into an aqueous solution, $3 \mathrm{~min}$ after phases mixture. Cohesion evaluated $1 \mathrm{~h}$ after injection: a) pristine material, b) simvastatin-loaded material. 


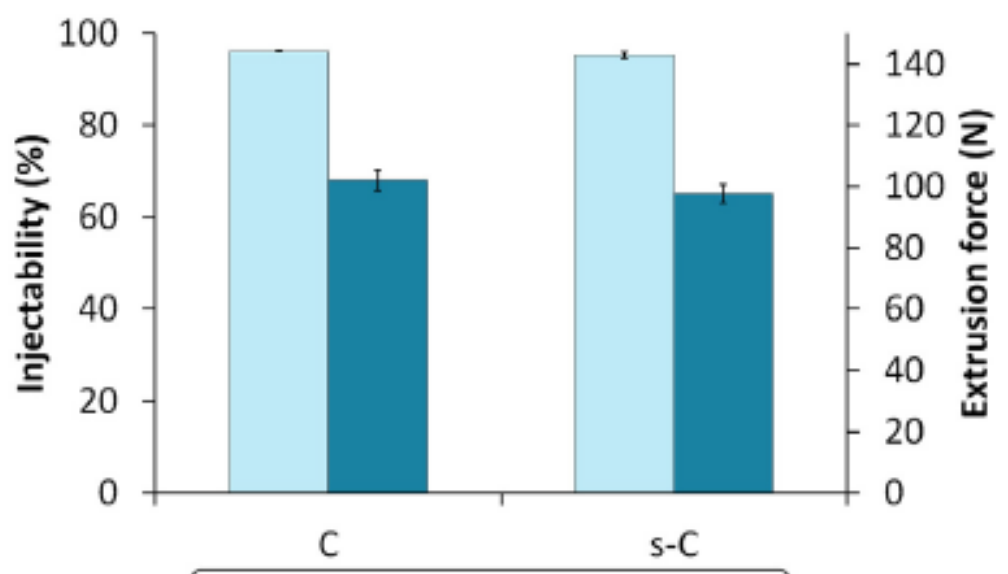

$\square$ Injectability $\quad$ Extrusion force

Fig. 3. Injectability and extrusion force of pristine cement (C) and simvastatin-loaded cement (s-C). 


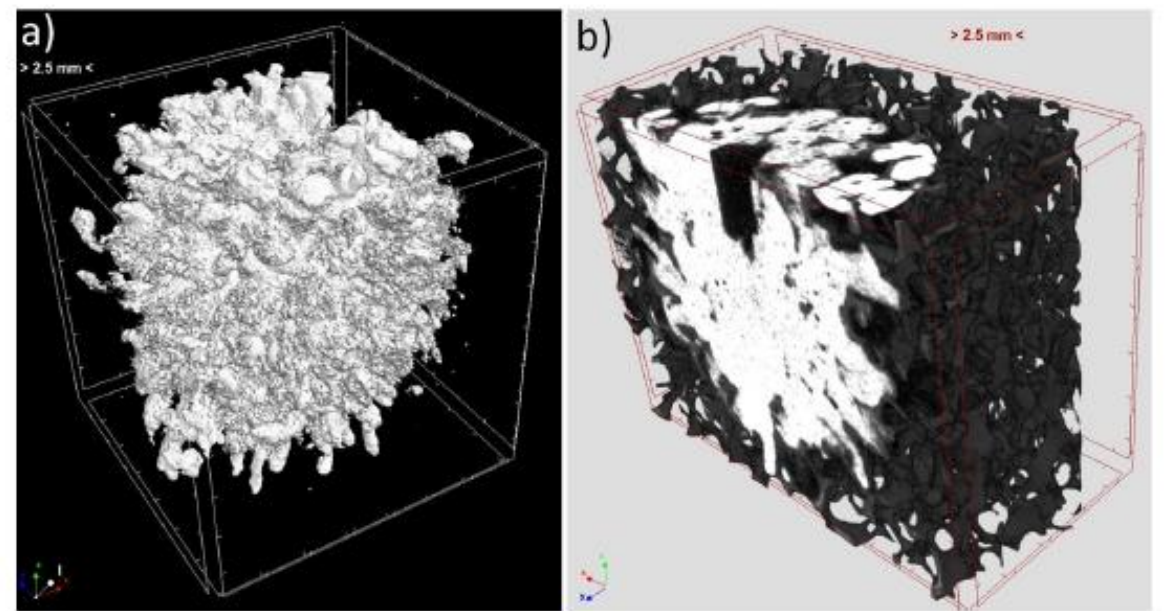

Fig 4. $\mu \mathrm{CT}$ images showing a pristine cement injected, a) entire foam, b) coronal section of image (a) in which the foam (dark grey) is containing the cement (white). 


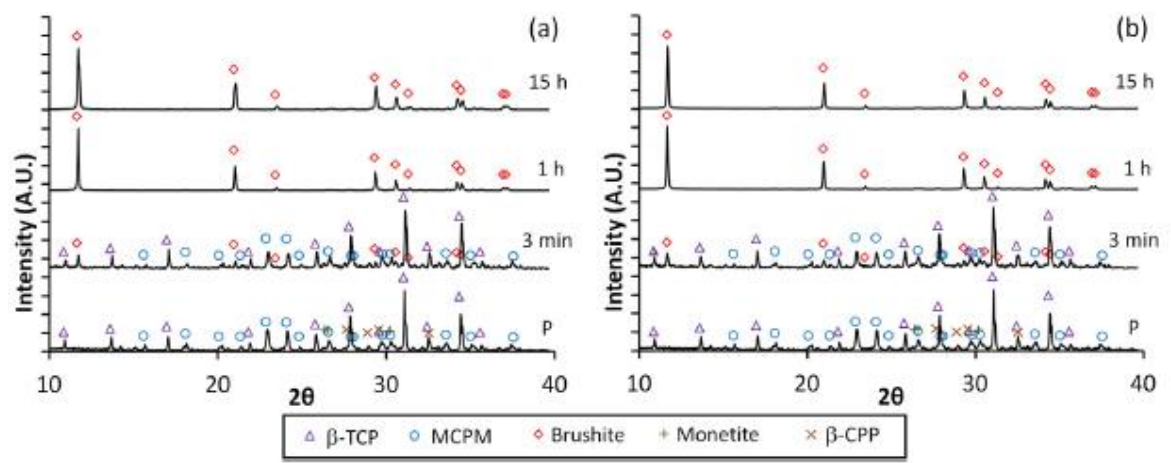

Fig 5. Evolution of thecrystal phases in situ For a) pristine cement and b) simvastatin-loaded cement. The initial powder ( $\mathrm{P}$ ), fresh cerment ( 3 min after mixing the phases), and cement set for $1 \mathrm{~h}$ and $15 \mathrm{~h}$ are displayed. 

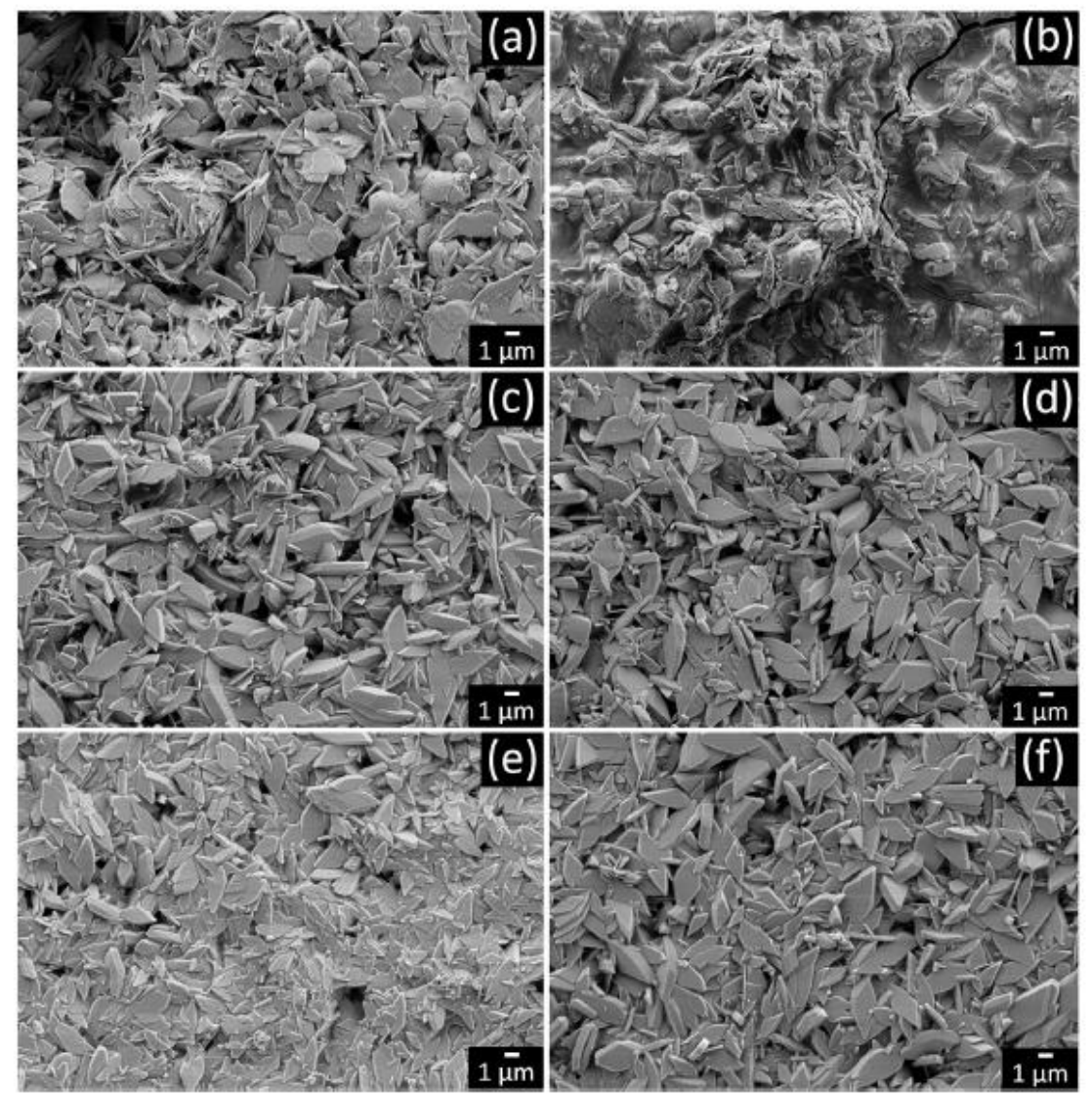

Fig. 6. SEM images of pristine cement a) fresh ( 3 min after mixing the phases), c) set for $1 \mathrm{~h}$ and e) set for $15 \mathrm{~h}$; and simvastatin-loaded cement b) fresh ( 3 min after mixing the phases). d) set for $1 \mathrm{~h}$ and $\mathrm{f}$ ) set for $15 \mathrm{~h}$. Images $\mathrm{a}$ and $\mathrm{b}$ are repre sentative morphologies found in both pristine and simvastatin-loaded cement, 


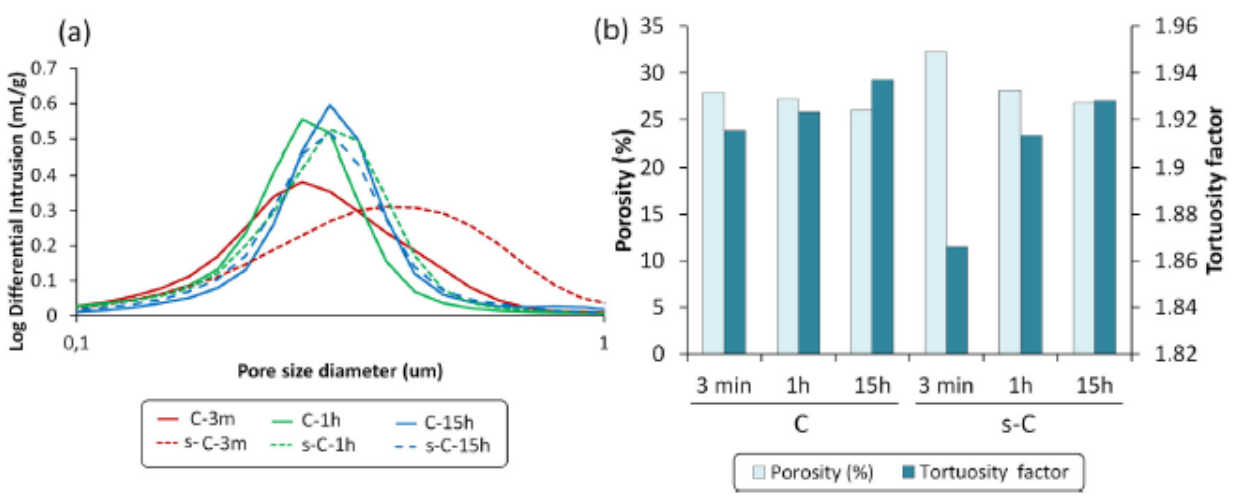

Fig.7. a) Pore size distribution and b) total porosity and tortuosity factor of pristine cements (C) and simvastatin-loaded cements (s-C) evaluated fresh ( 3 min after mixing the phases) and set for $1 \mathrm{~h}$ and $15 \mathrm{~h}$. 


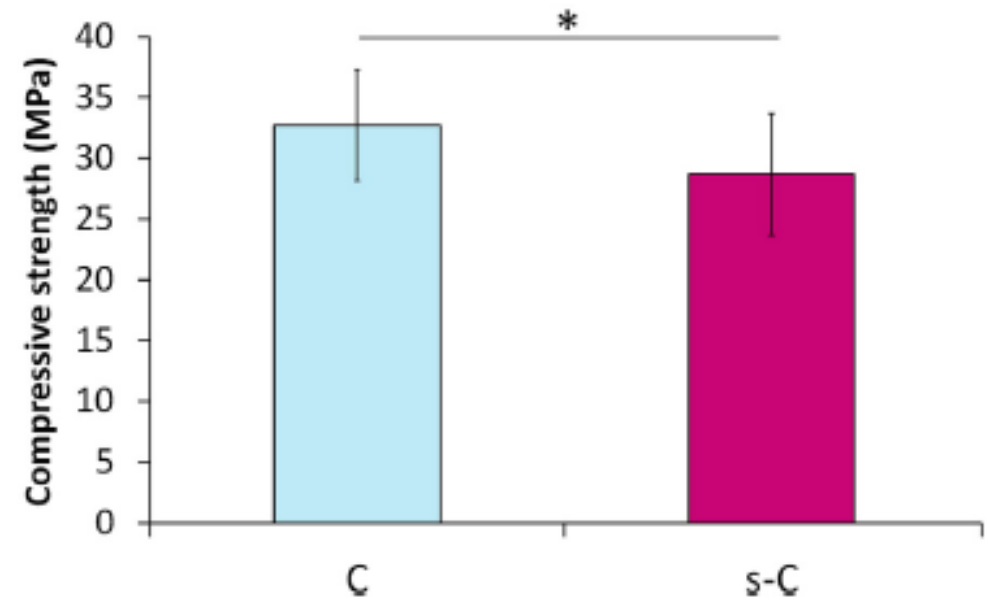

Fig. 8. Mechanical properties of pristine cement (C) and simvastatin-loaded cement ( $s-\mathrm{C}$ ) set for $15 \mathrm{~h}$ 


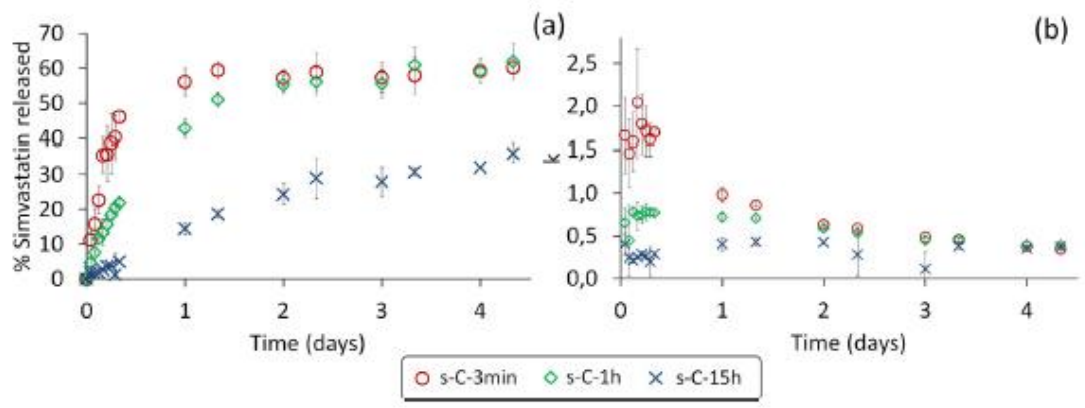

Fig 9. a) Release of simvas tatin from simvas tatin-loaded cements, fresh ( $3 \mathrm{~min}$ after mixing the phases) and set for $1 \mathrm{~h}$ and $15 \mathrm{~h}$ before immersing the samples in the release solution; b) parameter vs. release time considering a fixed $n$ value of 0.77 . 